\title{
Microstructure and Properties of ZLIOI Alloy Affected by Substrate Movement Speed of a Novel Semisolid Continuous Micro Fused-Casting for Metal Process
}

\author{
LUO Xiaoqiang", ${ }^{1,2}$ HAN Yongjun' ${ }^{*}$, LI Qingbin', HU Xiaoming', XUE Lingwei' \\ (1.Pingdingshan University, Pingdingshan 467000, China;2.Institute of Mechanics, Chinese Academy of Sciences, Beijing 100190, China)
}

\begin{abstract}
A novel semisolid continuous Micro Fused-Casting additive manufacturing technology for producing a ZL101 alloy strip was developed, Micro Fused-Casting means that the semisolid metal slurry was pressed out from the outlet of bottom of crucible to the movable plate. The degree of sub-cooling was easily provided by movement of substrate in the micro fused-casting area. Under the aid of 3D manufacturing software, the ZL101 alloy strip was solidified and formed layer by layer. The microstructure and properties of ZL101 semisolid slurry were improved by the cooling conditions. The results showed that the ZL101 alloy strip samples fabricated by Micro Fused-Casting had uniform structures and good performances with the substrate movement speed at $20 \mathrm{~mm} / \mathrm{s}$ and the temperature at $590{ }^{\circ} \mathrm{C}$, the ultimate tensile strength and elongation of the ZL101 alloy strip reached $242.59 \mathrm{MPa}$ and $7.71 \%$, while the average Vickers hardness was $82.55 \mathrm{HV}$.
\end{abstract}

Key words: micro fused-casting; ZL101 alloy; semisolid; substrate movement speed; additive manufacturing

\section{Introduction}

As one of the lightest structural materials, aluminum alloy has received widespread interests because of its advantages of high specific strength, good machinability, superior damping capacity, and high thermal conductivity. These properties make aluminum alloys valuable in a system of applications including aerospace components, automobile for reducing the mass of transportation, and reducing the fuel consumption and air pollution ${ }^{[1-4]}$. Semisolid processing is a near-netshape metal forming process. In particular, semisolid forming is an ideal way to fabricate aluminum alloy products because of good flow ability ${ }^{[5,6]}$. Now, many slurry preparation processes have been developed, such as Magneto Hydro Dynamic (MHD) stirring, mechanical stirring and melt conditioner direct chill casting ${ }^{[2,7,8]}$.

Micro fused-casting for metal without mold molding technology is a new kind of technology in the field

(C) Wuhan University of Technology and Springer-Verlag GmbH Germany, Part of Springer Nature 2018

(Received: Dec. 29, 2016; Accepted: Mar. 25, 2018)

LUO Xiaoqiang(罗晓强): Ph D;Assoc.Prof.; E-mail:lxq.5566 @163.com

*Corresponding author: HAN Yongjun(韩永军): Ph D; Prof.; E-mail: hyj73@126.com

Funded by the National Natural Science Foundation of China (No. 51341009) of additive manufacturing technology, which usually needs a metal liquid as raw material ${ }^{[9-11]}$. The effective semisolid slurry preparation method is a characteristic of micro fused-casting for metal (MFCM) process. The machine of the MFCM process mainly includes a crucible and a stirring apparatus, and a horizontal movable plate ${ }^{[12]}$. During the process, a liquid alloy is poured into the crucible under the proper temperature, with the high stirring, the semisolid slurry is prepared, the semisolid slurry in the gap is forced to flow along the movement direction, then the cooling caused by the movement of horizontal movable plate, the semisolid slurry is transformed into a strip material ${ }^{[13,14]}$. In this paper a novel semisolid micro fused-casting for metal process based on MFCM process was developed. The process has two advantages. First, the energy consumption is much less than the normal roll-casting because the temperature of semisolid slurry is much lower than that of liquid alloys. Second, the microstructure of the alloy produced by the process is mainly composed of fine non-dendrites, and the mechanical properties of the product are better than that of a strip produced by conventional process.

In this work, the ZL101 alloy strip was prepared by MFCM. As a new technique, the ZL101 alloy strip indicates high performance, short course and net-shape. In the process, the effects of the substrate movement 
speed by MFCM on the microstructure and mechanical property of ZL101 alloy have been studied.

\section{Experimental}

\subsection{Principle of MFCM}

The process principle of MFCM is shown in Fig.1. It consists of a heating furnace, a heating system with a crucible heating and a movable plate. During the process, the uniform semisolid slurry is prepared in crucible heating and pressured though a nozzle to a fused-casting zone, an open flat space between the nozzle and the plate with diameter in millimeters and thickness in millimeters. Then, the plate, served as cooler and crystallizer, moves horizontally in a withdrawn out of the fused-casting zone. Controlled by the 3D controlling system, liquid metal is filled and solidified in given patterns layer by layer, and then a metal part is formed. Between the mouth and crystallization plate cavity area, the metallic melts begin to solidify rapidly, and the dendrite rapidly forms by metallic melts. In the process, the substrate movement speed has great effect on the slurry of metals by undercooling.

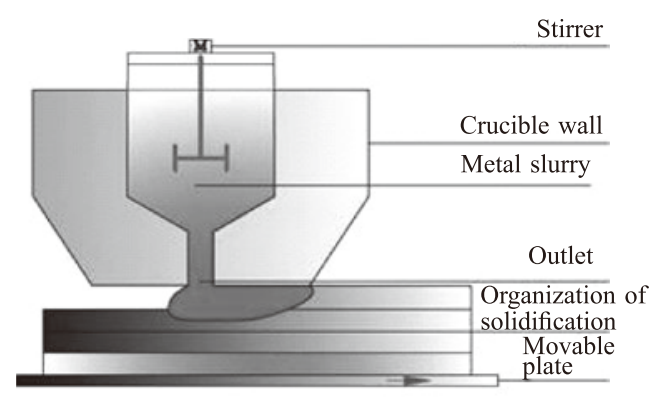

Fig.1 Micro fused-casting for metal liquid

\subsection{Material}

In this experiment, a commodity ZL101 aluminum silicon cast alloy was used with density of 2.66 $\mathrm{kg} / \mathrm{m}^{3}$. The experimental material was a Al-Si alloy whose main chemical composition (mass fraction,\%) was $\mathrm{Si} 7.51, \mathrm{Fe} 0.60, \mathrm{Mg} 0.25, \mathrm{Zn} 0.19$ and $\mathrm{Al}$ balanced.

\subsection{Alloy preparation}

In order to obtain fine and globular microstructure, the ZL101 aluminum alloys were heated to a temperature between liquids and solidus zone which was the sufficient condition required for the forming. In this experiment, we choosed the movement of substrate at different speed with the pouring temperature at 590 ${ }^{\circ} \mathrm{C}$. The samples for microstructure observation were prepared by standard metallographic techniques. The microstructures observation samples were cut off from the quenched slurries, roughly ground, polished and etched by an aqueous solution of $0.5 \% \mathrm{HF}$ for $15 \mathrm{~s}$, the etched samples were cleaned with an alcohol and dried, then analyzed by optical microscopy(OM), and the representative microstructure of the slurry can be obtained. All the metallographic samples were examined by OM, SEM(scanning electronic microscopy) and EDS(energy dispersive spectroscopy).

Therefore, the substrate movement at proper speed to get a high-performance products was determined, and the sample of ZL101 alloy for tensile test was produced.

\subsection{Testing methods}

The average grain size was calculated by

$$
D=\frac{L_{f}}{N_{f} \times \mu}
$$

where $D$ is the average grain size, $N_{\mathrm{f}}$ is the grain count, $L_{\mathrm{f}}$ is the length of measured line that is covered by the measured line and $\mu$ is the magnification value.

The average roundness of the grain shape was calculated by

$$
S=\frac{L_{p}^{2}}{4 \pi A_{p}}
$$

The average roundness of the grain shape was calculated by image analysis software. The $S$ is the average roundness, $L_{\mathrm{P}}$ and $A_{\mathrm{P}}$ are total circumference of measure grains and grain areas value of globule, respectively.

ZL101 cast alloy has been used for making tensile test samples. The samples for mechanical property tests were obtained from middle region, the samples were machined to specimens, and the tensile test was carried out by a CMT5105 tensile machine. The hardness was tested by a XHB-3000 Brilled durometer. The results reported in this work were the average values obtained from the test samples.

\section{Results and discussion}

\subsection{Differential scanning thermal analysis}

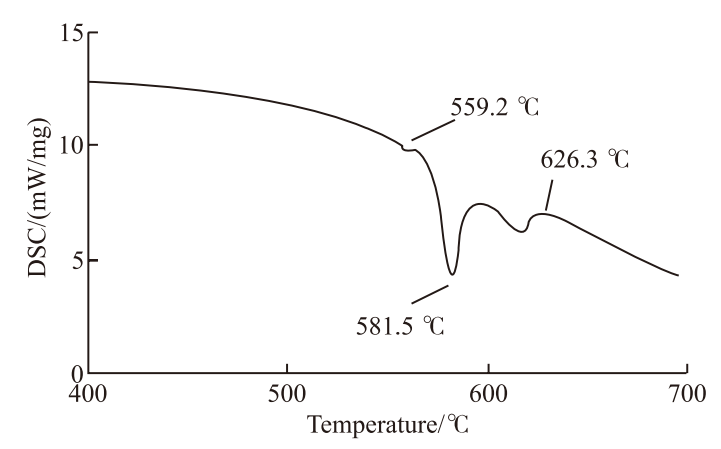

Fig.2 DSC curve of ZL 101 


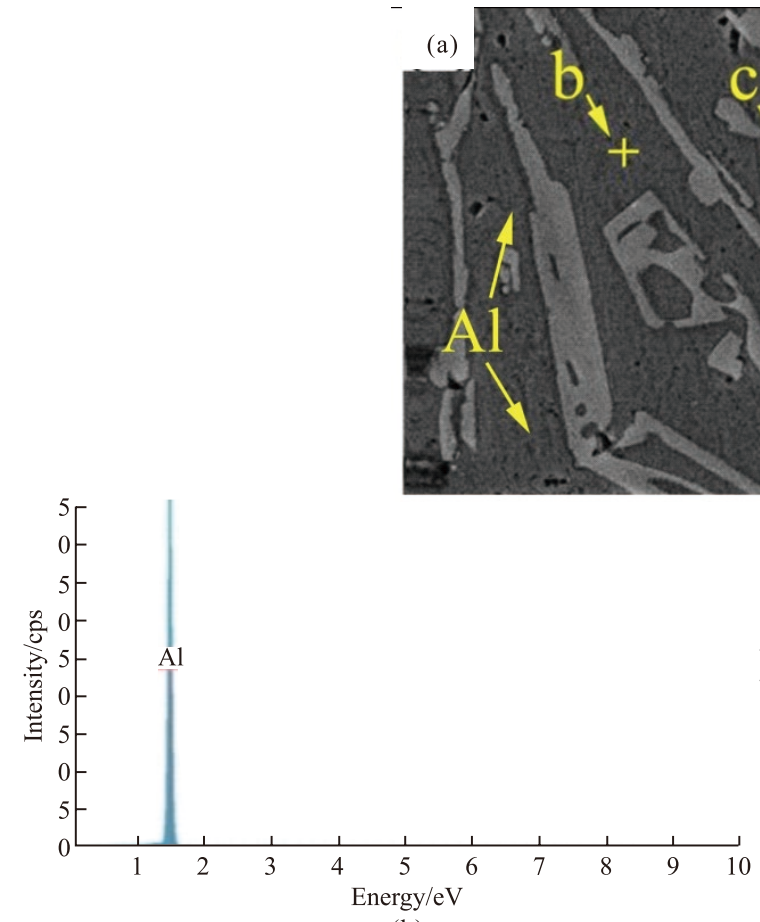

(b)

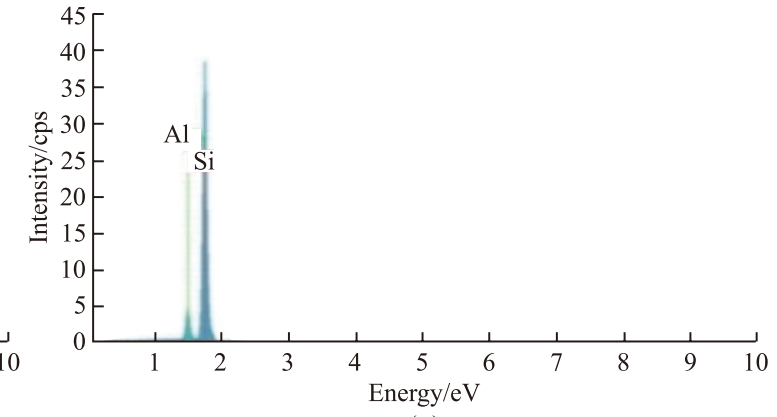

(c)

Fig. 3 SEM image of ZL101 alloy material: (a)SEM of material; (b) the energy spectrum test results of position b; (c) the energy spectrum test results of position $\mathrm{c}$

The relationship between the solid volume fraction and the temperature of the commercial ZL101 aluminum alloy was measured by differential scanning calorimetry (DSC). The commodity ZL101 aluminum silicon cast alloy was heated to $700{ }^{\circ} \mathrm{C}$ at $5{ }^{\circ} \mathrm{C} / \mathrm{min}$. The heat flow and temperature were tested by a K-type thermocouple to obtain DSC curves as shown in Fig.2. The solidus and liquidus temperatures of this alloy were 559.2 and $626.3{ }^{\circ} \mathrm{C}$, respectively.

\subsection{Microstructure of the ZLIOI alloy material}

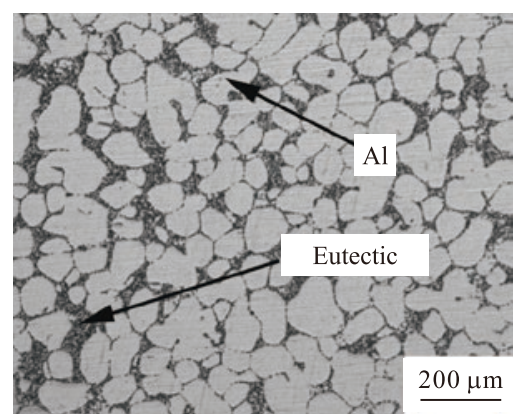

Fig.4 OM images of the ZL101 semisolid experimental alloy

Fig.4 shows the backscattered electron (BSE) image and EDS spectra of the sample with two regions of ZL101 aluminum alloys which exhibits typical dendritic microstructure. Furthermore, it is found from the BSE image that the white needle-shaped precipitates are $\mathrm{Si}$, the shine precipitates are $\mathrm{AlSi}_{9} \mathrm{Mg}$ (point $\mathrm{c}$ ), the grey precipitates are $\alpha-\mathrm{Al}$ (point $\mathrm{b}$ ), and the microstructure of ZL101 alloy is mainly composed of matrix $\alpha$-A and eutectic Si phases. According to the EDS results of ZL101 aluminum alloy, it is confirmed that the white needle-shaped precipitates and the grey precipitates in Fig. 3 are eutectic Si and eutectic $\alpha$-Al phases, respectively. It is found from Fig. 3 that the ZL101 aluminum alloy has microstructure in complex irregular shape, the $\mathrm{Si}$ phase is needle-shaped and the $\alpha-\mathrm{Al}$ is grey precipitates alloy mainly exhibiting a large block shape.

\subsection{Microstructure of the ZLIOI semisolid alloy and strip sample}

During the MFCM process, preparation of semisolid melts for Micro Fused-Casting using the temperature control and mixing system, the dendrite becomes short grain under the action of shear force in the areas of graphite crucible. After the ZL101 semisolid alloys slurry was cast into the collective crucible through the mouth of nozzle, the slurry and collective crucible were quenched in cold water rapidly to obtain the high temperature solidification microstructure. Fig. 4 shows the optical microstructure images of the samples produced at the pouring temperature of $590{ }^{\circ} \mathrm{C}$. The process of MFCM is focused on solidification. In the process, preparation of semisolid melts for Micro Fused-Casting has used the temperature control and mixing system. On the proper pouring temperature and stirring, the goal of fine grains was achieved. The globular fine grains distributed evenly in the structure of aluminum alloy.

The average grain size and roundness of the 
ZL101 semisolid alloys used in the experiment are 53 $\mu \mathrm{m}$ and 0.71 , respectively.
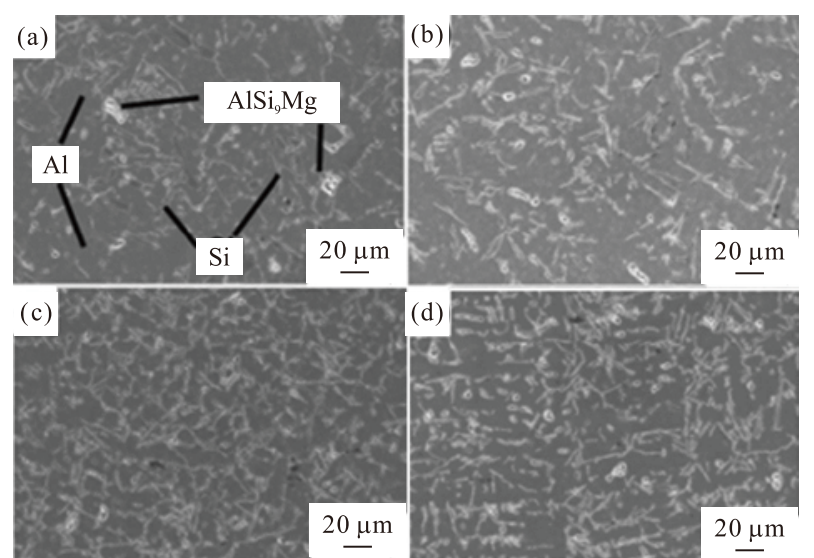

Fig.5 SEM images of the ZL101 experimental alloy treated at different substrate speed: (a) $10 \mathrm{~mm} / \mathrm{s}$, (b) $15 \mathrm{~mm} / \mathrm{s}$, (c) 20 $\mathrm{mm} / \mathrm{s}$, (d) $25 \mathrm{~mm} / \mathrm{s}$

Fig.5 shows the scanning electron microscopy of four samples. Fig.5(a) is the substrate with speed at 10 $\mathrm{mm} / \mathrm{s}$, Fig.5(b), Fig.5(c) and Fig.5(d) are the substrate with speed at $15,20,25 \mathrm{~mm} / \mathrm{s}$ respectively, while the pouring temperature of the nozzle exit is $590{ }^{\circ} \mathrm{C}$. The samples were high temperature molded without cold working besides cooling (T1 state). It was proved that dendrite breakage and nucleation were the main reasons of fine spherical micro-structure formation. Pouring temperature combined with melt undercooling can affect the dendrite fusing and grain shape of the melt, and its impact on grain size is obvious. The experiment with the pouring temperature at $590{ }^{\circ} \mathrm{C}$ and substrate speed at $20 \mathrm{~mm} / \mathrm{s}$ has a uniform microstructure and very few dendritic. Obviously, the substrate speed at $15 \mathrm{~mm} / \mathrm{s}$ and $25 \mathrm{~mm} / \mathrm{s}$ has segregation, respectively. It can be concluded that the refinement of particles could increase the material strength significantly, but the segregation of microstructure could decrease the material strength.

\subsection{Microstructure and properties of the ZLIOI alloy produced by the process}

Fig.6 shows the relationships between the substrate speed and Vickers hardness. The Vickers hardness is best developed at $20 \mathrm{~mm} / \mathrm{s}$, the substrate speed and temperature can affect the nucleation rate and cooling rate of the melt in the fused-casting zones, and further influence the Vickers hardness of the ZL101 alloy. The nucleation rate decreased with increasing temperature and increasing speed from $10 \mathrm{~mm} / \mathrm{s}$. Furthermore, the nucleation rate of the ZL101 slurry increased with increasing increments of the substrate speed, and viscosity decreased correspondingly. As stated, the undercooling in the melt is determined by the substrate movement speed and temperature, so the substrate movement speed reduces with the decrease of the crystal size of ZL101 slurry. For this reason, a high substrate speed could have caused a high nucleation rate, which caused globular crystals formation. When the substrate speed of MFCM was between 20 $\mathrm{mm} / \mathrm{s}$ and $25 \mathrm{~mm} / \mathrm{s}$, many obvious big dendrites disappear in the microstructures of the ZL101 slurry, as shown in Figs.5(c) and 5(d). On the other side, the melt undercooling increased and nucleation rate increased with the enhance of substrate speed, and the vickers hardness increased respectively. Nevertheless, if the substrate speed was higher than $30 \mathrm{~mm} / \mathrm{s}$, the melt flow ability of the ZL101 slurry was very good, and the operation procedure usually failed. For these reasons, we suggested a reasonable fused-casting substrate speed at about $15-25 \mathrm{~mm} / \mathrm{s}$ when the pouring temperature of the nozzle opening was $590{ }^{\circ} \mathrm{C}$. From Fig. 7 it can be seen that the largest average vickers hardness is $82.55 \mathrm{HV}$, which is obtained at velocity of plate of $20 \mathrm{~mm} / \mathrm{s}$.

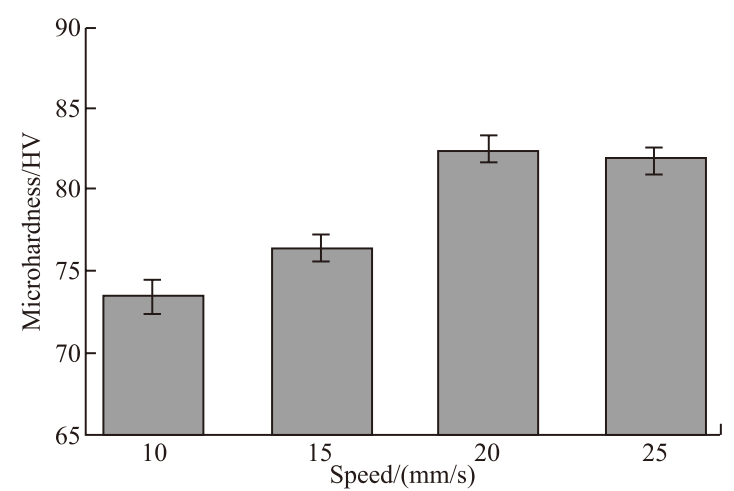

Fig.6 Vickers hardness chart of ZL101 alloy treated at different substrate speed

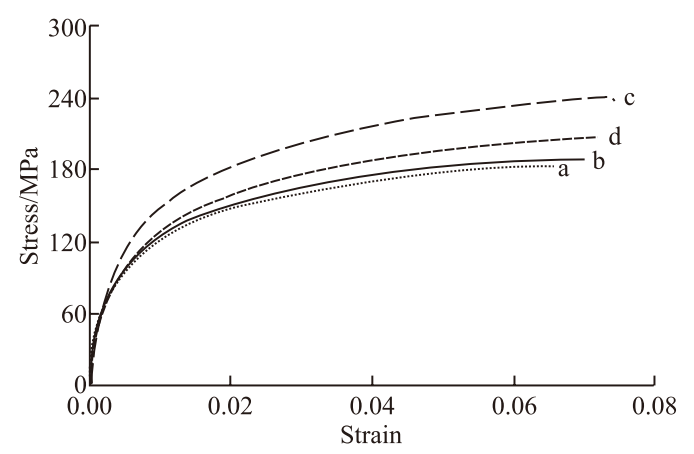

Fig.7 Tensile strength and elongation chart of ZL101 alloy strip treated at different substrate speed: (a) $10 \mathrm{~mm} / \mathrm{s}$, (b) 15 $\mathrm{mm} / \mathrm{s}$, (c) $20 \mathrm{~mm} / \mathrm{s}$, (d) $25 \mathrm{~mm} / \mathrm{s}$

Fig.7 shows the relationships between the substrate speed, tensile strength and elongation of the ZL101 alloy strip. At the fused-casting temperature 
of $590{ }^{\circ} \mathrm{C}$, and velocity of plate of $10,15,20$, and 25 $\mathrm{mm} / \mathrm{s}$, four kinds of metal strips were produced by fused-casting process. The surface of metal component was smooth. Therefore, the highest tensile strength is that of the metal components produced with the velocity of plate at $20 \mathrm{~mm} / \mathrm{s}$ and temperature at $590{ }^{\circ} \mathrm{C}$, the ultimate tensile strength and elongation of the ZL101 alloy strip have reached $242.59 \mathrm{MPa}$ and $7.71 \%$ at the substrate speed of $20 \mathrm{~mm} / \mathrm{s}$. Obviously, the pouring temperature at $590{ }^{\circ} \mathrm{C}$ and the substrate speed at 20 $\mathrm{mm} / \mathrm{s}$ could maintain the balance of melting and solidification of the material.

\section{Conclusions}

a) The experimental samples were prepared using aluminum alloy ZL101. The processing conditions of component formability and the organizational performance of ZL101 alloy were studied. The influences of parameters, such as the speed gradient on the microstructure evolution and mechanical property of ZL101 alloy by micro fused-casting for metal liquid were studied.

b) The microstructure and mechanical performance were excellent with the pouring temperature at $590{ }^{\circ} \mathrm{C}$ and the velocity of plate at $20 \mathrm{~mm} / \mathrm{s}$, the tensile strength and elongation of the ZL101 strip reached $242.59 \mathrm{MPa}$ and $7.71 \%$, respectively, and the Vickers hardness reached $82.55 \mathrm{HV}$.

\section{References}

[1] Amendola A, Hernández-Nava E, Goodall R, et al. On the Additive Manufacturing, Post-tensioning and Testing of Bi-material Tensegrity Structures[J]. Composite Structures, 2015, 131: 66-71

[2] Turner N B, Strong R, A. Gold S. A Review of Melt Extrusion Additive Manufacturing Processes: I. Process Design and Modeling[J]. Rapid Prototyping Journal, 2014, 20(3): 192-204
[3] Mazzolani F M. 3D Aluminium Structures[J]. Thin-Walled Structures, 2012, 61: 258-266

[4] Sercombe T B, Schaffer G B. Rapid Manufacturing of Aluminum Components[J]. Science, 2003, 301(5 637): $1225-1227$

[5] Eskin D G, Katgerman L. Mechanical Properties in the Semisolid State and Hot Tearing of Aluminium Alloys[J]. Progress in Materials Science, 2004, 49(5): 629-711

[6] Wu S, Xie L, Zhao J, et al. Formation of Non-dendritic Microstructure of Semisolid Aluminum Alloy under Vibration[J]. Scripta Materialia, 2008, 58(7): 556-559

[7] Turner B N, Gold S A. A Review of Melt Extrusion Additive Manufacturing Processes: II. Materials, Dimensional Accuracy, and Surface Roughness[J]. Rapid Prototyping Journal, 2015, 21(3): 250-261

[8] Aizenberg J, Muller D A, Grazul J L, et al. Direct Fabrication of Large Micropatterned Single Crystals[J]. Science, 2003, 299(5610): $1205-$ 1208

[9] Monaghan T, Capel A J, Christie S D, et al. Solid-state Additive Manufacturing for Metallized Optical Fiber Integration[J]. Composites Part A: Applied Science and Manufacturing, 2015,76: 181-193

[10] Thompson S M, Bian L, Shamsaei N, et al. An Overview of Direct Laser Deposition for Additive Manufacturing; Part I: Transport Phenomena, Modeling and Diagnostics[J]. Additive Manufacturing, 2015, 8: 3662

[11] Samanta A, Tuckerman M E, Yu T, et al. Microscopic Mechanisms of Equilibrium Melting of a Solid[J]. Science, 2014, 346(6210): 729-732

[12] Guan R, Chen L, Li J, et al. Dynamical Solidification Behaviors and Metal Flow During Continuous Semisolid Extrusion Process of AZ31 Alloy[J]. Journal of Materials Science \& Technology, 2009, 25(3): 395

[13] Luo X, Yan Q, Li Z. Effect of the Pouring Temperature by Novel Synchronous Rolling-casting for Metal on Microstructure and Properties of ZL104 Alloy[J]. Journal of Materials Research, 2016, 31(16): 2 5242530

[14] L Xiaoqiang, L Zhengyang, C Guangnan, et al. Effect of Substrate Movement Speed by Synchronous Rolling-casting Freeform Manufacturing for Metal on Microstructure and Mechanical Property of ZL104 Aluminum Alloy Slurry[J]. Journal of Wuhan University of Technology-Materials Science Edition, 2015(5): 1 056-1 060 